\title{
Protective effects of PEP-1-Catalase on stress-induced cellular toxicity and MPTP-induced Parkinson's disease
}

\author{
Seon Ae Eom ${ }^{1, \#}$, Dae Won Kim ${ }^{2, \#}$, Min Jea Shin ${ }^{1}$, Eun Hee Ahn ${ }^{1}$, Seok Young Chung ${ }^{1}$, Eun Jeong Sohn ${ }^{1}$, Hyo Sang Jo ${ }^{1}$, \\ Su-Jeong Jeon ${ }^{3}$, Duk-Soo Kim ${ }^{3}$, Hyeok Yil Kwon ${ }^{4}$, Sung-Woo Cho ${ }^{5}$, Kyu Hyung Han ${ }^{1}$, Jinseu Park ${ }^{1}$, Won Sik Eum ${ }^{1, *}$ E \\ Soo Young Choi ${ }^{1, *}$ \\ ${ }^{1}$ Department of Biomedical Science and Research Institute of Bioscience and Biotechnology, Hallym University, Chunchon 200-702, \\ ${ }^{2}$ Department of Biochemistry and Molecular Biology, Research Institute of Oral Sciences, College of Dentistry, Gangnung-Wonju National \\ University, Gangneung 210-702, ${ }^{3}$ Department of Anatomy, College of Medicine, Soonchunhyang University, Cheonan 330-090, \\ ${ }^{4}$ Department of Physiology, College of Medicine, Hallym University, Chunchon 200-702, ${ }^{5}$ Department of Biochemistry and Molecular \\ Biology, University of Ulsan College of Medicine, Seoul 138-736, Korea
}

\begin{abstract}
Parkinson's disease (PD) is a neurodegenerative disability caused by a decrease of dopaminergic neurons in the substantia nigra (SN). Although the etiology of PD is not clear, oxidative stress is believed to lead to PD. Catalase is antioxidant enzyme which plays an active role in cells as a reactive oxygen species (ROS) scavenger. Thus, we investigated whether PEP-1-Catalase protects against 1-methyl-4-phenylpyridinium $\left(\mathrm{MPP}^{+}\right)$induced SH-SY5Y neuronal cell death and in a 1-methyl-4-phenyl-1,2,3,6-trtrahydropyridine (MPTP) induced PD animal model. PEP-1-Catalase transduced into SH-SY5Y cells significantly protecting them against $\mathrm{MPP}^{+}$-induced death by decreasing ROS and regulating cellular survival signals including Akt, Bax, Bcl-2, and p38. Immunohistochemical analysis showed that transduced PEP-1-Catalase markedly protected against neuronal cell death in the SN in the PD animal model. Our results indicate that PEP-1-Catalase may have potential as a therapeutic agent for PD and other oxidative stress related diseases. [BMB Reports 2015; 48(7): 395-400]
\end{abstract}

\footnotetext{
*Corresponding authors. Soo Young Choi, Tel: +82-33-248-2112; Fax: +82-33-248-3201; E-mail: sychoi@hallym.ac.kr, Won Sik Eum, Tel: +82-33-248-2112; Fax: +82-33-248-3201; E-mail: wseum@ hallym.ac.kr

Present Address of Seok Young Chung : Shaker High School, Latham, NY 12110, USA

${ }^{\#}$ These authors contributed equally to this work.
}

http://dx.doi.org/10.5483/BMBRep.2015.48.7.197

Received 11 September 2014, Revised 24 September 2014, Accepted 16 October 2014

Keywords: Parkinson's disease, ROS, PEP-1-Catalase, Protein therapy, Dopaminergic neuron

\section{INTRODUCTION}

Parkinson's disease (PD) is a neurodegenerative disability which involves degeneration of substantia nigra (SN) leading to a deficiency of dopamine (1). Symptoms of PD include tremor, rigidity, muscle stiffness, bradykinesia, postural instability which may eventually lead to movement disorders (2). The etiologies include a lack of dopamine or an excess of acetylcholine in the brain. Similar symptoms are known to occur in cases of vascular disorders of the brain, neoplasm, and head injury (3). Although the mechanism of cellular death is not clearly understood, aging, inflammation, as well as chemical, and genetic factors in the development of the disorder appear to be involved with the onset of PD (1, 4-6).

Catalase is known as a major antioxidant enzyme which neutralizes the harmful effects of reactive oxygen species (ROS) and as such, is considered beneficial in the treatment of many disorders. Catalase protects cells through 2 processes: prevention of hydroxyl radical generation and by the separation of hydrogen peroxide into water and oxygen. Removing the oxygen free radicals is very important in maintaining the stabilized redox status of cells (7).

Protein transduction domains (PTDs) are small peptides which are capable of transducing macromolecules into cells and tissues without any specific receptors (8). A recent study demonstrated that transduced Tat-PRDX6 protein protects against eye lens epithelial cell death and delayed lens opacity, suggesting that protein transduction could be an effective approach to delaying eye disease (9). Previous studies by this group have demonstrated that PEP-1 fusion proteins efficiently transduce into various cells and protect against a variety of diseases including skin inflammation and neuronal diseases (10-17). Also, we demonstrated that PEP-1-Catalase transduced into astrocyte cells and protected against oxidative stress-induced cell death as well as ischemic injury (18).

In this study, we examined the protective effect of transduced PEP-1-Catalase in SH-SY5Y cells and in a PD animal 
model. PEP-1-Catalase transduced into SH-SY5Y cells and animal brain cells and offered significant protection against oxidative stress-induced cell death in vitro and in vivo. Therefore, we suggest that PEP-1-Catalase could be used as a therapeutic agent for various oxidative stress related disorders including PD.

\section{RESUTLS AND DISCUSSION}

\section{Purification and transduction of PEP-1-Catalase into SH-SY5Y cells}

Catalase is a major antioxidant enzyme found in almost every living organism and plays an important role in protecting cells from the damage induced by reactive oxygen species (ROS) $(7$, 19). Catalase has therefore been considered for therapeutic use

A

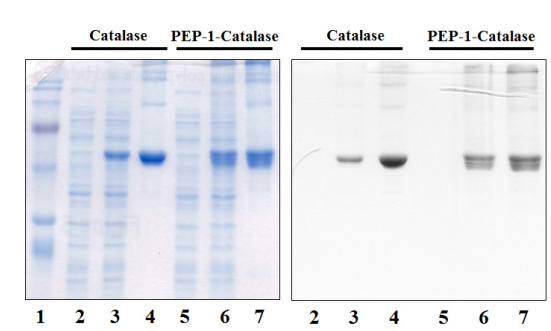

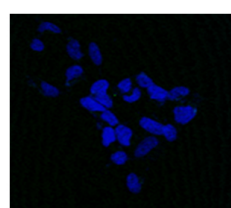

Control

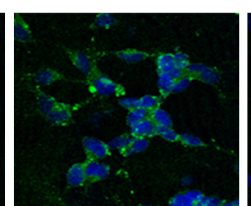

PEP-1-Catalase

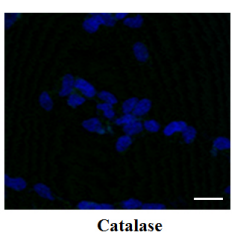

C

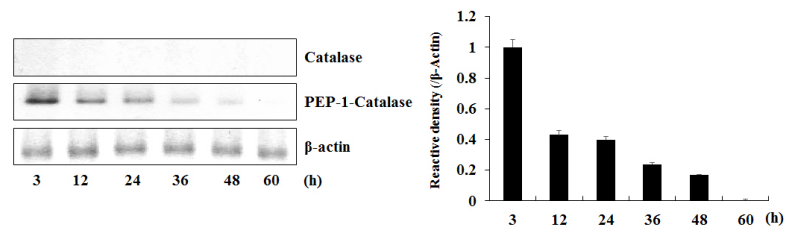

Fig. 1. Purification and transduction of PEP-1-Catalase into SH-SY5Y cells. (A) Expression and purification of PEP-1-Catalase and control catalase proteins were identified by $12 \%$ SDS-PAGE and Western blot analysis using an anti-His antibody. Lanes are as follows: lane 1, marker; lane 2 and 5, non-induced; lane 3 and 6, induced; lane 4 and 7, purified. (B) Localization of transduced PEP-1-Catalase confirmed by confocal fluorescence microscopy. After transduction of PEP-1-Catalase $(3 \mu \mathrm{M})$, the cells were examined by DAPI and Alexa staining. Scale bar $=50 \mu \mathrm{m}$. (C) The stability of transduced PEP-1-Catalase into SH-SY5Y cell. After PEP-1-Catalase $(3 \mu \mathrm{M})$ transduced into the cells were incubated for 3-60 $\mathrm{h}$ and analyzed by Western blotting and the band intensity was measured by densitometer. in ROS-related diseases.

Protein transduction domains (PTDs) have demonstrated their ability to deliver exogenous proteins into cells which has potential for targeting specific proteins, delivering them into living cells. There is also room for the examination of novel therapeutic proteins $(8,20)$. PEP-1-Catalase and control catalase proteins were expressed and purified as described previously (18) and were confirmed by SDS-PAGE and Western blot analysis using an anti-histidine antibody (Fig. 1A). In order to clearly confirm whether PEP-1-Catalase transduced into the cells, we used confocal fluorescence microscopy analysis using an His antibody, DAPI, and Alexa fluor-488 conjugated secondary antibody. As shown in Fig. 1B, strong fluorescence signals were detected in the PEP-1-Catalase treated cells while fluorescence signals were not detected in the control catalase treated cells.

We examined the stability of transduced PEP-1-Catalase in the cells. After transduction of PEP-1-Catalase $(3 \mu \mathrm{M})$ for $3 \mathrm{~h}$, the cells were incubated at various times up to 60 hours. We observed that intracellular levels of transduced PEP-1-Catalase persisted in the cells for $48 \mathrm{~h}$ (Fig. 1C). PEP-1-Catalase transduced into the cells in a dose- and time-dependent manner. However, control catalase did not transduce into the cells (data not shown). These results indicate that PEP-1-Catalase transduced into SH-SY5Y cells and remained stable in the cells for $48 \mathrm{~h}$.

Transduced PEP-1-Catalase protected against MPP ${ }^{+}$-induced cell death and cytotoxicity

1-Methyl-4-phenylpyidinium ion $\left(\mathrm{MPP}^{+}\right)$is known to induce ROS in dopaminergic neuronal cells which then leads to DNA fragmentation and eventually to cell death (21-23). $\mathrm{MPP}^{+}$, the active metabolite of 1-methyl-4-phenyl-1,2,3,6-tetrahydropyridine (MPTP), has been used extensively in PD experiments as a classic neurotoxin for its ability to induce PD-like symptoms including loss of dopaminergic cells damage and death (24-26). Therefore, we confirmed whether transduced PEP-1-Catalase can protect against $\mathrm{MPP}^{+}$-induced $\mathrm{SH}-\mathrm{SY} 5 \mathrm{Y}$ cell death. As shown in Fig. 2A, transduced PEP-1-Catalase markedly increased cell viability in a concentration dependent manner, up to $76 \%$. On the other hand, cell viability was roughly the same as the cells treated with $\mathrm{MPP}^{+}$alone $(46 \%)$ compared with control catalase treated cells ( $52 \%)$.

We examined whether transduced PEP-1-Catalase inhibits $\mathrm{MPP}^{+}$-induced intracellular ROS generation and DNA fragmentation using DCF-DA and TUNEL staining. Cells treated with $\mathrm{MPP}^{+}$showed higher intensity of fluorescence compared to control cells demonstrating $\mathrm{MPP}^{+}$-induced intracellular ROS generation. In the control catalase treated cells, the amount of ROS generation was similar to the $\mathrm{MPP}^{+}$treated control cells. However, transduced PEP-1-Catalase markedly inhibited the level of intracellular ROS generation by $\mathrm{MPP}^{+}$(Fig. 2B). As shown in Fig. 2C, transduced PEP-1-Catalase also significantly inhibited the DNA fragmentation. These results indicate that 


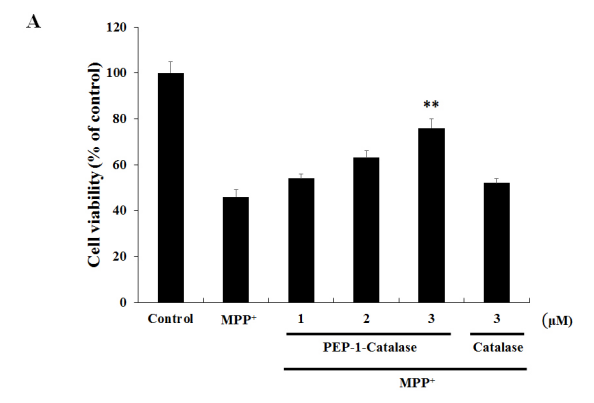

B
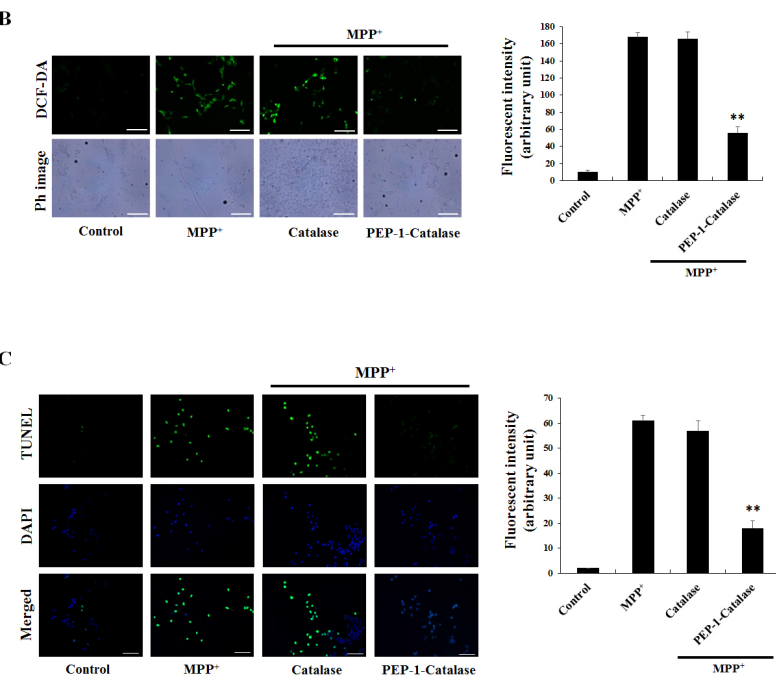

Fig. 2. Inhibitory effects of PEP-1-Catalase against cell death and cytotoxicity by $\mathrm{MPP}^{+}$. (A) After pre-processing with $3 \mu \mathrm{M}$ of PEP-1-Catalase and control catalase protein for $3 \mathrm{~h}$ into SH-SY5Y cells, (A) cell viability, (B) intracellular ROS levels, and (C) DNA fragmentation were detected by MTT assay, DCF-DA and TUNEL staining, respectively, as described in Materials and Methods. Scale bar $=50 \mu \mathrm{m} .{ }^{* * P}<0.01$, compared with $\mathrm{MPP}^{+}$-treated cells.

transduced PEP-1-Catalase efficiently protects against $\mathrm{MPP}^{+}$-induced $\mathrm{SH}-\mathrm{SY} 5 \mathrm{Y}$ cell death and DNA fragmentation by inhibiting intracellular ROS levels.

Transduced PEP-1-Catalase regulation of cell survival signaling Next, we confirmed whether transduced PEP-1-Catalase effects cellular survival signaling induced by $\mathrm{MPP}^{+}$. Several studies have demonstrated that the cellular damage induced by $\mathrm{MPP}^{+}$ results from increased phosphorylation of Akt, Bax, and p38 expression levels with a corresponding decrease in anti-apoptotic protein, Bcl-2 expression levels in the cells $(27,28)$. As shown in Fig. 3, the expression levels of phosphorylation of Akt, Bax, and p38 were markedly increased by MPP ${ }^{+}$. However, cells treated with transduced PEP-1-Catalase demonstrated dose-dependent decreased phosphorylation of Akt, Bax, and p38 expression levels. At the same time, the expression levels of $\mathrm{Bcl}-2$ were significantly decreased in cells treated with
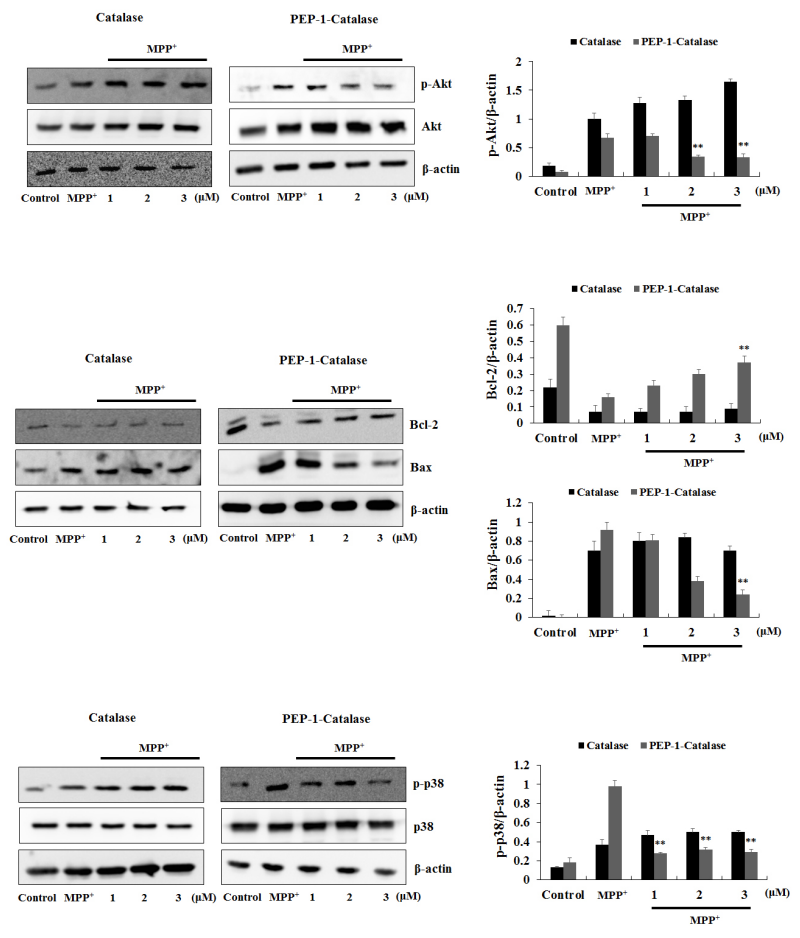

Fig. 3. Effects of PEP-1-Catalase against $\mathrm{MPP}^{+}$-induced cell survival signals in SH-SY5Y cells. After treatment of SH-SY5Y cells with 3 $\mu \mathrm{M}$ of PEP-1-Catalase and control catalase proteins, the cells were treated with $4 \mathrm{mM}$ of $\mathrm{MPP}^{+}$for $10 \mathrm{~min}$ (p-Akt), $3 \mathrm{~h}$ (Bax and $\mathrm{BCl}-2)$, and $35 \mathrm{~min}$ (p-p38), respectively. The indicated protein levels were measured by Western blot analysis and the band intensity were measured by densitometer. ${ }^{*} \mathrm{P}<0.01$, compared with $\mathrm{MPP}^{+}$-treated cells.

$\mathrm{MPP}^{+}$while transduced PEP-1-Catalase increased Bcl-2 expression levels.

The expression of several cell survival proteins including Bax, Bcl-2, Akt, p38 have been shown to be regulated by ROS and their importance in cell survival has also been well documented $(22,24,25,28)$. Akt is also known to be a cell survival mediator and studies have demonstrated that the expression levels of these survival proteins were influenced by exposure to $\mathrm{MPP}^{+}$(27-29). Consistent with other studies, we demonstrated that PEP-1-Catalase regulates cell survival signals and protects against $\mathrm{MPP}^{+}$-induced $\mathrm{SH}-\mathrm{SY} 5 \mathrm{Y}$ cell death. However, further studies are needed to examine the exact mechanism.

PEP-1-Catalase transduced into mouse brain and protected dopaminergic neuron in a PD animal model

Since the blood-brain barrier (BBB) prevents entry of therapeutic proteins to brain, transduce into brain of therapeutic protein is important to protein therapy. Thus, we examined whether PEP-1-Catalase protects against MPTP-induced dopaminergic neuronal cell death. Cell viability was evaluated by immunohistochemistry using a tyrosine hydroxylase (TH) anti- 
A
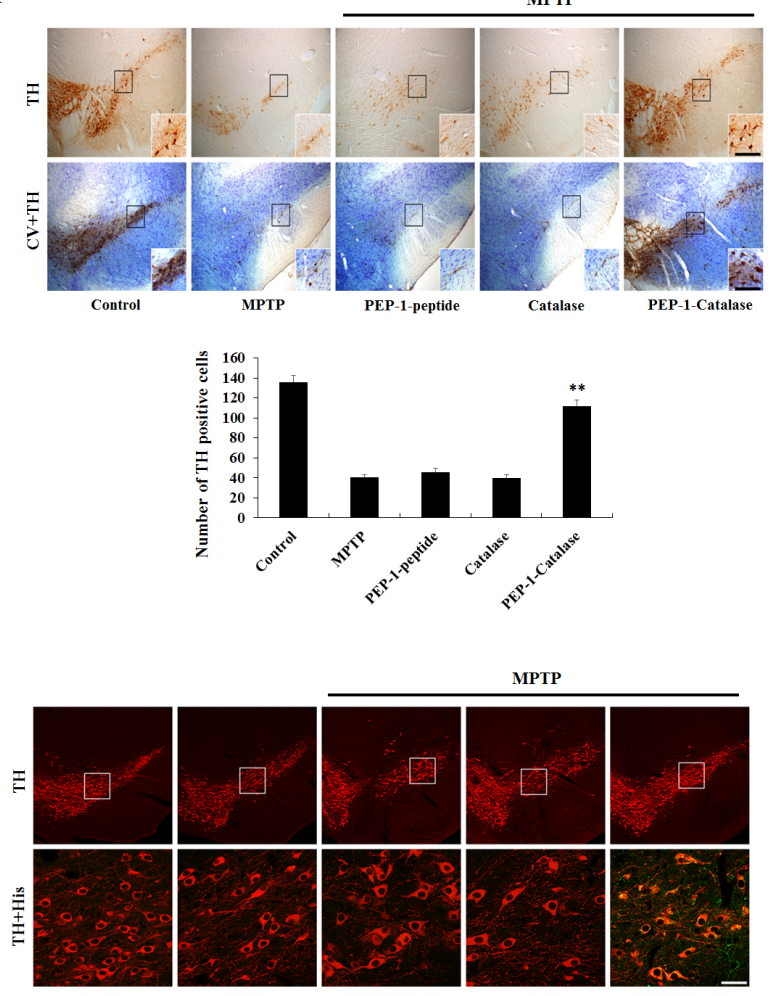

Control

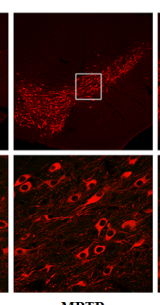

MPTP

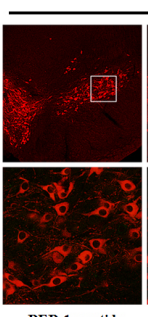

PEP-1-peptide
MPTP

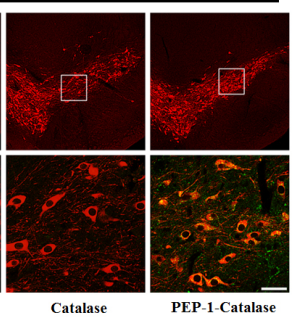

Fig. 4. Effect of PEP-1-Catalase on dopaminergic neuronal cell death in PD animal model. (A) Protective effect is confirmed by staining immunoreactivity neuron with tyrosine hydroxylase $(\mathrm{TH})$ and cresyl violet (CV) in MPTP-induced PD mice model. Scale bar $=100 \mu \mathrm{m}$ and $50 \mu \mathrm{m}$. (B) Localization of PEP-1-Catalase is confirmed by double-staining with $\mathrm{His}$ and $\mathrm{TH}$ antibody, as described in Materials and Methods. DA neurons (anti-TH), red; PEP-1-catalase (anti-His), green. Scale bar $=100 \mu \mathrm{m}$ and $18.8 \mu \mathrm{m}$.

body and cresyl violet (CV) staining (Fig. 4A). In the MPTPtreated mice, dopaminergic neuronal cell death was significantly increased compared to the sham control-treated mice. In addition, in the control catalase-treated and PEP-1 peptide-treated mice, dopaminergic neuronal cell death was similar to those of MPTP-treated mice. However, in the PEP-1Catalase-treated mice, dopaminergic neuronal cell viability significantly increased and showed similar level compared to sham control mice.

We further examined transduced PEP-1-Catalase localization in the substantia nigra $(\mathrm{SN})$ region. PEP-1-Catalase $(2 \mathrm{mg} / \mathrm{kg})$ was i.p. injected into mice before MPTP treatment. Brain tissue samples were obtained $12 \mathrm{~h}$ after MPTP injection and double-stained with a $\mathrm{TH}$ antibody (red) and an His antibody (green). As shown in Fig. 4B, there is no difference in the $\mathrm{TH}$ staining between the sham control and others groups. However, green fluorescent staining was only detected in the

PEP-1-Catalase-treated group. Our results demonstrated that PEP-1-Catalase efficiently crossed the BBB and markedly protected against MPTP-induced dopaminergic neuronal cell death. In agreement with our results, other studies have demonstrated that overexpression of antioxidant proteins significantly protects against dopaminergic neuronal cell death in PD models (30).

In conclusion, PEP-1-Catalase efficiently transduced into neuronal cells and protected against oxidative stress-induced dopaminergic neuronal cell death in vitro and in vivo. Though further study will be necessary to understand the precise mechanism our results show that PEP-1-Catalase has potential in the treatment of ROS-related diseases including PD.

\section{MATERIALS AND METHODS}

\section{Materials and cell culture}

PEP-1-Catalase and control catalase protein were constructed, overexpressed, and purified as described previously (18). The primary p38, p-p38, Akt, p-Akt, Bax, and Bcl-2 rabbit antibodies were purchased from Cell signaling (Denvers, MA, USA). His rabbit primary antibody and secondary anti-rabbit antibody were obtained from Santa Cruz Biotechnology (CA, USA). Unless otherwise stated, all other chemicals and reagents were purchased from Sigma-Aldrich (St. Louis, MO, USA) and were of the highest quality analytical grade accessible.

The SH-SY5Y human neuroblastoma cells were preserved in Eagle's Minimum Essential Medium (EMEM; Lonza, MD, USA) including 10\% fetal bovine serum (FBS; Gibco BRL, Grand Island, NY, USA) and antibiotics $(100 \mu \mathrm{g} / \mathrm{ml}$ streptomycin 100 $\mathrm{U} / \mathrm{ml}$ penicillin; Gibco BRL) at $37^{\circ} \mathrm{C}$ in a humidified atmosphere containing $95 \%$ air and $5 \% \mathrm{CO}_{2}$.

\section{Westem blot analysis}

For Western blot analysis, equal amounts of proteins in each cell lysate were resolved by $12 \%$ sodium dodecyl sulfate-polyacrylamide gel electrophoresis (SDS-PAGE). The resolved proteins were electrotransfered to a nitrocellulose membrane, which was then blocked with $5 \%$ non-fat dry milk in TBS-T buffer $(25 \mathrm{mM}$ Tris-HCl, $140 \mathrm{mM} \mathrm{NaCl}, 0.1 \%$ Tween 20, pH 7.5). The membrane was incubated with a rabbit anti-histidine, p38, p-p38, Akt, p-Akt, Bax, and Bcl-2 primary antibodies (dilution 1:1,000; Cell Signaling) and a horseradish peroxidase-conjugated secondary antibody (dilution 1:10,000; Santa Cruz). Enhanced chemiluminescent reagents were used to visualize protein bands, according to the manufacturer's instructions (Amersham, Piscataway, NJ, USA).

\section{Cell viability assay}

A cell viability assay was performed using 3-(4,5-dimethylathiazol-2-yl)-2,5- diphenyltetrazolium bromide (MTT) as described previously $(10,13)$. Cells were plated in a 96-well plate and treated with PEP-1-Catalase $(1-3 \mu \mathrm{M})$ for $3 \mathrm{~h}$. Then the cells 
were washed with PBS and incubated with 1-methyl-4-phenyridinium $\left(\mathrm{MPP}^{+}\right) 4 \mathrm{mM}$ for $17 \mathrm{~h}$. MTT solution was administered to each well. After $4 \mathrm{~h}$ of incubation, the precipitated formazan crystal was dissolved in dimethyl sulfoxide and absorbance was measured at $570 \mathrm{~nm}$ using an ELISA microplate reader (Lab systems Multiskan MCC/340). Cell viability was defined as the percentage of control cells.

\section{Confocal fluorescence microscopy}

For detection of transduced PEP-1-Catalase in SH-SY5Y cells, Confocal fluorescence microscopy was performed as described previously $(10,13)$. The cells were seeded on coverslips after which they were exposed to PEP-1-Catalase and control catalase protein $(3 \mu \mathrm{M})$ for $3 \mathrm{~h}$. Cells were then washed with PBS twice and fixed with $4 \%$ paraformaldehyde at room temperature for $5 \mathrm{~min}$. The cells were incubated with an anti-histidine primary antibody and an Alexa Fluor 488-conjugated secondary antibody (Invitrogen; Carlsbad, CA, USA). Nuclei were stained for $5 \mathrm{~min}$ with $1 \mu \mathrm{g} / \mathrm{ml} \mathrm{4'6-diamidino-}$ 2-phenylindole (DAPI; Roche Applied Science, Basel, Switzerland). An Olympus FV-300 confocal fluorescence microscope (Olympus, Tokyo, Japan) was used to analyze fluorescence images.

\section{Measurement of intracellular ROS level}

Intracellular ROS levels were determined using 2'7'-dichlorofluorescein diacetate (DCF-DA) staining as described previously $(10,13)$. After being incubated with PEP-1-Catalase or control catalase protein $(3 \mu \mathrm{M})$ for $3 \mathrm{~h}$, SH-SY5Y cells were exposed to $\mathrm{MPP}^{+}(4 \mathrm{mM})$ for $40 \mathrm{~min}$. Cells were then washed twice with PBS and stained with DCF-DA $(30 \mu \mathrm{M})$ for $30 \mathrm{~min}$. Photomicrographs of each sample were taken using an Eclipse 80i fluorescence microscope (Nikon, Tokyo, Japan). Under the same experimental conditions, the fluorescence intensity was quantified using a Fluoroskan ELISA plate reader (Labsystem Oy, Helsinki, Finland).

\section{Terminal deoxynucleotidyl transferase-mediated dUTP nick end labeling (TUNEL) staining}

DNA fragmentation was determined using TUNEL staining as described previously $(10,13)$. SH-SY5Y cells were incubated on coverslips with PEP-1-Catalase or control catalase protein (3 $\mu \mathrm{M})$ for $3 \mathrm{~h}$, after which they were treated with $\mathrm{MPP}^{+}(4 \mathrm{mM})$ for $14 \mathrm{~h} 30 \mathrm{~min}$. A Cell Death Detection kit (Roche Applied Science, Basel, Switzerland) was used to perform TUNEL staining according to the manufacturer's instructions. Fluorescence micrographs were produced using an Eclipse 80i fluorescence microscope (Nikon, Tokyo, Japan). Under the same experimental conditions, the fluorescence intensity was quantified using a Fluoroskan ELISA plate reader (Labsystem Oy, Helsinki, Finland).

\section{PD animal model}

Male, 6-week-old, C57BL/6 mice were obtained from the
Hallym University Experimental Animal Center. The animals were housed at a constant temperature $\left(23^{\circ} \mathrm{C}\right)$ and relative humidity $(60 \%)$ with an alternating $12 \mathrm{~h}$ light-dark cycle. They were provided free access to food and water. All procedures regarding animals and their care conform to the Guide for the Care and Use of Service of Korea and were approved by the Hallym Medical Center Institutional Animal Care and Use Committee.

An animal PD model was prepared as described in previous studies (13). The mice ( $n=5 /$ each group) were divided into five groups; 1) non-treated sham controls, 2) MPTP-treated, 3) MPTP + PEP-1 peptide-treated, 4) MPTP + control catalase-treated, 5) MPTP + PEP-1-Catalse-treated. The mice received four injections of MPTP $(20 \mathrm{mg} / \mathrm{kg}$ ) at $2 \mathrm{~h}$ intervals. To determine the protective effects of PEP-1-Catalase against PD, mice were single i.p. injected with PEP-1-Catalase $(2 \mathrm{mg} / \mathrm{kg})$ $12 \mathrm{~h}$ before the MPTP injection. 7 days after the last injection, mice were euthanized for immunohistochemistry.

To examine the localization of PEP-1-Catalase in the SN of mice, animal PD models were prepared as described above. Mouse brains were harvested $12 \mathrm{~h}$ later and immunohistochemistry was performed.

\section{Immunohistochemistry}

Immunostaining was performed as described in previous studies (13). Sections were blocked with $3 \%$ bovine serum albumin in PBS at room temperature for 30 min and then were incubated with an His antibody for detection of PEP-1-Catalase or with a tyrosine hydroxylase $(\mathrm{TH})$ antibody to detect DA neurons. To detect viable cells, cresyl violet counter-staining for Nissl bodies was carried out after TH-immunostaining. The sections were visualized with 3,3'-diaminobenzidine in a 0.1 $M$ Tris buffer and mounted on gelatin-coated slides. Images were taken and analyzed using an Olympus DP72 digital camera and DP2-BSW microscope digital camera software. Figures were prepared using Adobe Photoshop version 7.0 (San Jose, CA, USA).

\section{Statistical analysis}

Data are expressed as the means \pm SD from three independent experiments. Differences among means were analyzed using one-way ANOVA. Newman-Keuls post hoc analysis was employed when differences in ANOVA testing were observed $(\mathrm{P}<0.01)$.

\section{ACKNOWLEDGEMENTS}

This work was supported by a Priority Research Centers Program grant (NRF-2009-0093812) through the National Research Foundation of Korea funded by the Ministry of Science, ICT \& Future Planning in the Republic Korea and by a research grant from Hallym University (HRF-2014-08-012) and in part by a academic research development grant of Gangnung-Wonju National University (2014). 


\section{REFERENCES}

1. Moore DJ, West AB, Dawson VL and Dawson TM (2005) Molecular pathophysiological of Parkinson's disease. Annu Rev Neurosci 28, 57-87

2. Dawson TM and Dawson VL (2003) Molecular pathways of neurodegeneration in Parkinson'sdisease. Science 302, 819-822

3. Chinta SJ and Andersen JK (2008) Redox imbalance in Parkinson'sdisease. Biochim Biophys Acta 1780, 13621367

4. Hunot S and Hirsch EC (2003) Neuroinflammatory processes in Parkinson's disease. Ann Neurol 53, S49-S60

5. Dauer W and Przedborski S (2003) Parkinson's disease: mechanisms and models. Neuron 39, 889-909

6. Henchcliffe C and Beal MF (2008) Mitochondrial biology and oxidative stress in Parkinson disease pathogenesis. Nat Clin Pract Neurol 4, 600-609

7. Halliwell B and Gutteridge JM (1990) Role of free radicals and catalytic metal ions in human diseases: an overview. Methods Enzymol 186, 1-85

8. van den Berg A and Dowdy SF (2011) Protein transduction domain delivery of therapeutic macromolecules. Curr Opin Biotechnol 22, 888-893

9. Kubo E, Fatma N, Akagi Y, Beier DR, Singh SP and Singh DP (2008) TAT-mediated PRDX6 protein transduction protects against eye lens epithelial cell death and delays lens opacity. Am J Physiol Cell Physiol 294, C842-C855

10. Kim MJ, Jeong HJ, Kim DW et al (2014) PEP-1-PON1 protect regulates inflammatory response in Raw 264.7 macrophages and ameliorates inflammation in a TPA-induced animal model. PLoS One 9, e86034

11. Ahn EH, Kim DW, Shin MJ et al (2013) Fenobam promoted the neuroprotective effect of PEP-1-FK506BP following oxidative stress through increasing its transduction efficiency. BMB Rep 46, 561-566

12. An JJ, Eum WS, Kwon HS et al (2013) Protective effects of skin permeable epidermal and fibroblast growth factor against ultraviolet-induced skin damage and human skin wrinkles. J Cosmet Dermatol 12, 287-295

13. Ahn EH, Kim DW, Shin MJ et al (2013) PEP-1-ribosomal protein S3 protects dopaminergic neurons in an MPTP-induced Parkinson's disease mouse model. Free Radic Biol Med 55, 36-45

14. Kwon SW, Sohn EJ, Kim DW et al (2011) Anti-inflammatory effect of transduced PEP-1-heme oxygenase-1 in Raw 264.7 cells and a mouse edema model. Biochem Biophys Res Commun 411, 354-359

15. Shin MJ, Kim DW, Lee YP et al (2014) Tat-glyoxalase protein inhibits against ischemic neuronal cell damage and ameliorates ischemic injury. Free Radic Biol Med 67, 195-210

16. Kim SY, Sohn EJ, Kim DW et al (2011) Transduced PEP-1-FK506BP ameliorates atopic dermatitis in NC/Nga mice. J Invest Dermatol 131, 1477-1485

17. Kim DW, Lee SH, Ku SK et al (2013) Transduced PEP-1FK506BP ameliorates corneal injury in Botulinum toxin A-induced dry eye mouse model. BMB Rep 46, 124-129
18. Kim DW, Jeong HJ, Kang HW et al (2009) Transduced human PEP-1 - catalase fusion protein attenuates ischemic neuronal damage. Free Radic Biol Med 47, 941-952

19. Mates M (2000) Effects of antioxidant enzymes in the molecular control of reactive oxygen species toxicology. Toxicology 153, 83-104

20. Wadia JS and Dowdy SF (2002) Protein transduction technology. Curr Opin Biotechnol 13, 52-56

21. Kaul S, Kanthasamy A, Kitazawa M, Anantharam V and Kanthasamy AG (2003) Caspase-3 dependent proteolytic activation of protein kinase $C \delta$ mediates and regulates 1-methyl-4-phenylpyridinium $\left(\mathrm{MPP}^{+}\right)$-induced apoptotic cell death in dopaminergic cells: relevance to oxidative stress $\mathrm{n}$ dopaminergic degeneration. Eur J Neurosci 18, 1387-1401

22. Zhu JH, Horbinski C, Guo F, Watkins S, Uchiyama $Y$ and Chu CT (2007) Regulation of autophagy by extracellular signal-regulated protein kinases during 1-methyl-4-phenylpyridinium-induced cell death. Am J Pathol 170, 75-86

23. Choi WS, Canzoniero LM, Sensi SL et al (1999) Characterization of $\mathrm{MPP}^{+}$-induced cell death in a dopaminergic neuronal cell line : role of macromolecule synthesis, cytosolic calcium, caspase, and Bcl-2-related proteins. Exp Neurol 159, 274-282

24. Hu S, Han R, Mak S and Han Y (2011) Protection against 1-methyl-4-phenyl pyridinium ion $\left(\mathrm{MPP}^{+}\right)$-induced apoptosis by water extract of ginseng (Panax ginseng C.A. Meyer) in SH-SY5Y cells. J. Ethnopharmacol 135, 34-42

25. Choi WS, Yoon SY, Oh TH, Choi EJ, O'Malley KL and Oh YJ (1999) Two distinct mechanisms are involved in 6-hydroxydopamine- and $\mathrm{MPP}^{+}$-induced dopaminergic neuronal cell death: role of caspases, ROS, and JNK. J Neurosci Res 57, 86-94

26. Martin HL, Mounsey RB, Mustafa S, Sathe K and Teismann P (2012) Pharmacological manipulation of peroxisome proliferator-activated receptor $\gamma$ (PPAR $\gamma$ ) reveals a role for anti-oxidant protection in a model of Parkinson's disease. Exp Neurol 235, 528-538

27. Fuenzalida K, Quintanilla R, Ramos P et al (2007) Peroxisome proliferator-activated receptor gamma up-regulates the $\mathrm{BCl}-2$ anti-apoptotic protein in neurons and induces apoptosis. J Biol chem 282, 37006-37015

28. Hashimoto $R, Y u J$, Koizumi $H$, Ouchi $Y$ and Okabe $T$ (2012) Ginsenoside Rb1 prevents MPP ${ }^{+}$-induced apoptosis in PC12 cells by stimulating estrogen receptors with consequent activation of ERK1/2, Akt and inhibition of SAPK JNK, p38 MAPK. Evid Based Complement Alternat Med Med 2012, 693717

29. Burke RE (2007) Inhibition of mitogen-activated protein kinase and stimulation of Akt kinase signaling pathways: two approaches with therapeutic potential in the treatment of neurodegenerative disease. Pharmacol Ther 114 261-277

30. Shukla AK, Pragya P, Chaouhan HS et al (2014) Heat shock protein-70 (Hsp-70) suppresses paraquat-induced neurodegenration by inhibiting JNK and caspase-3 activation in Drosophila model of Parkinson's disease. PLoS One 9, e98886 